\title{
When reciprocity fails: effort-reward imbalance in relation to coronary heart disease and health functioning within the Whitehall II study
}

\author{
H Kuper, A Singh-Manoux, J Siegrist, M Marmot
}

See end of article for authors' affiliations

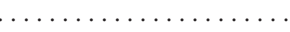

Correspondence to: Dr H Kuper, International Centre for Health and Society, Department of Epidemiology and Public Health, University College London, 1-19 Torrington Place, London WC1E 6BT, UK;

hannahk@public-health. ucl.ac.uk

Accepted 26 April 2002
Background: A deleterious psychosocial work environment, as defined by high efforts expended in relation to few rewards reaped, is hypothesised to increase the risk of future poor health outcomes. Aims: To test this hypothesis within a cohort of London based civil servants.

Methods: Effort-reward imbalance (ERI) was measured among 6895 male and 3413 female civil servants aged 35-55 during the first phase of the Whitehall II study (1985-88). Participants were followed until the end of phase 5 (1997-2000), with a mean length of follow up of 11 years. Baseline ERI was used to predict incident validated coronary heart disease (CHD) events during follow up and poor mental and physical functioning at phase 5 .

Results: A high ratio of efforts in relation to rewards was related to an increased incidence of all CHD (hazard ratio $(\mathrm{HR})=1.36,95 \% \mathrm{Cl} 1.12$ to 1.65 ) and fatal $\mathrm{CHD} /$ non-fatal myocardial infarction $(\mathrm{HR}=1.28,95 \% \mathrm{Cl} 0.89$ to 1.84$)$ during follow up, as well as poor physical (odds ratio $(O R)=1.47$, $95 \% \mathrm{Cl} 1.24$ to 1.74$)$ and mental $(O R=2.24,95 \% \mathrm{Cl} 1.89$ to 2.65$)$ functioning at phase 5 , net of employment grade. A one item measure of high intrinsic effort also significantly increased the risk of these health outcomes, net of grade. ERI may be particularly deleterious with respect to CHD risk among those with low social support at work or in the lowest employment grades.

Discussion: Within the Whitehall II study, a ratio of high efforts to rewards predicted higher risk of $\mathrm{CHD}$ and poor physical and mental health functioning during follow up. Although the increased risk associated with ERI was relatively small, as ERI is common it could be of considerable public health importance.
E vidence has accumulated linking psychosocial factors, including work characteristics, to the incidence of and prognosis after coronary heart disease (CHD), ${ }^{1}$ the number one killer in high income countries. ${ }^{2}$ As a result of this research the general public has become concerned about the effect of work stress on health, and the lay press, which reports frequently on this topic, bolsters this concern. Given the complexity and variability of stressful experience at work it is essential to identify its "toxic" components with the help of theoretical models. Two such models have received special attention. The demand control model developed by Karasek posits that high psychological demands at work in combination with low control (in terms of skill utilisation and decision latitude) elicit sustained high stress at work. ${ }^{34}$ A complementary concept, Siegrist's model of effort-reward imbalance (ERI), is concerned with distributive justice, that is, the balance between effort spent and rewards received in a core social role in adult life, the work role. ${ }^{5}$

As the ERI model will be the main topic of this contribution it needs to be introduced in more detail. Since reciprocal exchange underlies all transactions in society, digression from this reciprocity is argued to produce a condition of stress. In the workplace reciprocity depends on a balance between perceived efforts spent (extrinsic effort), in terms of psychological and physical demands, and rewards received in turn. This social contract operates with three types of reward: money, esteem, and career opportunities including job security. Following from this, when people believe that they have expended high effort, but perceive they have reaped few rewards, a condition of emotional distress will be produced. As a result of this failed reciprocity, the risk of stress related mental and physical illness would increase. The cardiovascular system is vulnerable to continuously enhanced activation of the autonomic nervous system following exposure to high cost/low gain conditions. ${ }^{6}$ Therefore, effort-reward imbalance at work is expected to increase the risk of CHD.

Clearly some people are better at coping with stressful situations than others, and the ERI model can incorporate this. For instance, people with "overcommitment", or high intrinsic effort, will exaggerate their efforts because of their desire for esteem and approval, and will find the discrepancy between efforts and rewards particularly stressful. ${ }^{57}$ In addition, high levels of social support at work may provide strain relief and could allow people to cope better with adverse work characteristics. ${ }^{89}$ As people with lower socioeconomic positions have fewer material resources to buffer the effects of stress on health, they may suffer more from adverse health consequences as a result of a stressful work environment. ${ }^{8-10}$ We therefore hypothesise that an individual pattern of overcommitment at work, low socioeconomic position, and a low level of social support at work will augment the impact of work related stressful experience on health.

Poor psychosocial factors often cluster in people exposed to traditional CHD risk factors and with lower socioeconomic positions. We are therefore challenged to test the argument that any association between psychosocial factors and CHD is the result of inadequate control for confounding by health behaviours or social class. ${ }^{11}$ The Whitehall II study provides a valuable opportunity to address this question. First, employment grade within Whitehall II provides us with an excellent

Abbreviations: $\mathrm{BMI}$, body mass index; $\mathrm{CHD}$, coronary heart disease; ERI, effort-reward imbalance; HR, hazard ratio; $\mathrm{MI}$, myocardial infarction; OR, odds ratio; SES, socioeconomic status 
Table 1 Phase 1 effort-reward imbalance

\begin{tabular}{ll}
\hline & \\
\hline Extrinsic effort* & Factor loadings \\
Do you have to work very fast? & 0.70 \\
Do you have to work very intensively? & 0.82 \\
Do you have enough time to do everything? & 0.59 \\
Does your work demand a high level of skill and expertise? & 0.68 \\
Does your job require you to take the initiative? & 0.66 \\
Reward $†$ & \\
Do you ever get praised for your work? & 0.48 \\
Does your job provide you with a variety of interesting things? & 0.63 \\
Do you consider your job very important? & 0.60 \\
Do your colleagues consider your job very important? & 0.61 \\
How often do you get help and support from your colleagues? & 0.41 \\
How often do you get help and support from your immediate superior? & 0.44 \\
How satisfied are you with your usual take home pay? & 0.30 \\
How satisfied are you with your work prospects? & 0.62 \\
How satisfied are you with the way your abilities are used? & 0.72 \\
How satisfied are you with the interest and skill involved in your job? & 0.73 \\
\hline *Cronbach's alpha = 0.72; †Cronbach's alpha = 0.75. & \\
\end{tabular}

measure of the socioeconomic status (SES) of the individual, taking into account the material, social, and prestige components of social position. Second, high effort at work in relation to low rewards is more common, but CHD less common, in the higher employment grades in the British Civil Service. Therefore, if a positive association exists between ERI and CHD in Whitehall II it could not be the result of confounding by social class, since confounding by social class would produce an association between high ERI and low CHD incidence. Third, detailed information has been collected about adverse health behaviours and traditional coronary risk factors. ${ }^{12}$

Previous work published by the Whitehall II study showed that ERI predicts incident self reported $\mathrm{CHD}^{13}$ psychiatric disorder, ${ }^{14}$ and poor health functioning ${ }^{15}$ during follow up. In the time since these papers were published there has been a refinement of the concept of ERI. We have therefore developed a new scale to measure efforts and rewards that is more in line with the current theory. In addition, the present analyses are based on extended follow up and use validated CHD outcomes. We have also evaluated the association between ERI and health functioning to test whether the results for ERI and CHD are consistent for other health outcomes.

\section{METHODS}

\section{Study population}

The Whitehall II study is a new cohort of civil servants that was established between 1985 and 1988 (phase 1). All non-industrial civil servants aged 35-55 years who worked in the London offices of 20 departments were sent an introductory letter and screening questionnaire, and were offered a screening examination for cardiovascular disease. The overall response rate was $73 \%$, but the true response rate was probably higher, since about $4 \%$ of the civil servants on the lists provided by the civil service had moved before the study and were therefore ineligible for inclusion. In total 10308 civil servants participated, of whom 67\% (6895) were men and 33\% (3413) were women. Participants were approached again in 1989-90 (phase 2: postal questionnaire, 8129 respondents), in 1991-93 (phase 3: postal questionnaire and screening examination, 8548 respondents), in 1995-96 (phase 4: postal questionnaire, 8700 respondents), and in 1997-99 (phase 5: postal questionnaire and screening examination, 7830 respondents). The median length of follow up from phase 1 to phase 5 was 11 years. We obtained written informed consent from all participants as part of the questionnaire. Ethical approval for the Whitehall II study was obtained from the University College London Medical School Committee on the ethics of human research.

\section{Coronary heart disease events}

A total of 10300 (99.9\%) participants were flagged at the National Health Service Central Registry, who notified us of the date and cause of death. Participants were defined as having a coronary death if the underlying cause had an ICD-9 code 410-414. ${ }^{16}$ Potential non-fatal myocardial infarction (MI) and angina events were ascertained by questionnaire items on: chest pain (the World Health Organisation Rose questionnair ${ }^{17}$ ), recall of a doctor's diagnosis, investigation (exercise electrocardiography, stress imaging, or angiography) and treatment (nitrates or revascularisation). We sought details of physician diagnoses and investigation results from clinical records for all potential cases of MI and angina. Twelve lead resting electrocardiograms were performed at study phases 1 , 3, and 5 (Simmons Mingorec) and classified according to the Minnesota code. ${ }^{17}{ }^{18}$ Two independent trained coders carried out the classification of MI and angina, with adjudication by a third coder in the (rare) event of disagreement. In total 931 incident cases of all CHD (angina, fatal CHD, and non-fatal MI) and 300 incident cases of fatal CHD and non-fatal MI were included. Fatal CHD and non-fatal MI were grouped together as they were considered "hard" end points, unlikely to be misclassified. There were 70 people with a history of non-fatal MI and 421 people with a history of non-fatal MI or angina at phase 1 .

\section{Health functioning}

We assessed health related quality of life or functioning at phase 5 by the UK standard version of the Short-Form 36 Health Survey (SF-36)..$^{19}$ Detailed information on the use of SF-36 in the Whitehall study has been reported elsewhere. ${ }^{20}$ The original eight scales of SF-36 can be summarised into physical and mental functioning components by a method based on factor analysis. ${ }^{21}$ These two conceptually distinct components have been used to assess health functioning in this paper, with the lowest quartile indicating poor functioning.

\section{Effort-reward imbalance scale}

The ERI scale in its current form was not available at phase 1, but it was part of the phase 5 questionnaire. ${ }^{22-24}$ We therefore had to derive the phase 1 ERI scale using the phase 5 data as the starting point. Exploratory factor analyses were performed on phase 1 work characteristics measures to identify items 


\begin{tabular}{|c|c|c|}
\hline & Men & Women \\
\hline \multicolumn{3}{|l|}{ Age (years) } \\
\hline$\geqslant 39-<45$ & $1.06(0.21)$ & $1.00(0.23)$ \\
\hline$\geqslant 45-<50$ & $1.07(0.21)$ & $0.99(0.23)$ \\
\hline$\geqslant 50-<55$ & $1.06(0.21)$ & $0.96(0.24)$ \\
\hline$\geqslant 55-<64$ & $1.05(0.22)^{*}$ & $0.95(0.25)^{\text {** }}$ \\
\hline Administrative & $1.10(0.18)$ & $1.09(0.19)$ \\
\hline Professional & $1.06(0.22)$ & $1.03(0.21)$ \\
\hline Clerical & $0.93(0.26)^{* *}$ & $0.90(0.25)^{* *}$ \\
\hline Home owner & $1.07(0.21)$ & $0.99(0.23)$ \\
\hline Non-home owner & $0.97(0.24)$ ** & $0.91(0.25)^{\text {** }}$ \\
\hline Car owner & $1.07(0.21)$ & $0.98(0.23)$ \\
\hline Non-car owner & $1.02(0.24)^{* *}$ & $0.96(0.25)^{* *}$ \\
\hline Never smoker & $1.06(0.21)$ & $0.97(0.24)$ \\
\hline Former smoker & $1.06(0.21)$ & $0.99(0.23)$ \\
\hline Current smoker 1-10 & $1.04(0.20)$ & $0.98(0.24)$ \\
\hline Current smoker $11-20$ & $1.04(0.25)$ & $0.94(0.25)$ \\
\hline Current smoker $\geqslant 20$ & $1.06(0.20)$ & $0.98(0.26)^{*}$ \\
\hline Non-drinker & $1.03(0.24)$ & $0.95(0.24)$ \\
\hline Below limit & $1.07(0.21)$ & $0.98(0.24)$ \\
\hline Above limit & $1.06(0.21)^{* *}$ & $1.05(0.26)^{* *}$ \\
\hline$<1.5 \mathrm{~h}$ exercise/wk & $1.05(0.24)$ & $0.95(0.25)$ \\
\hline$\geqslant 1.5 \mathrm{~h}$ exercise/wk & $1.07(0.20)^{* *}$ & $0.99(0.23)^{* * *}$ \\
\hline$<20 \mathrm{BMI}$ & $1.04(0.20)$ & $1.01(0.26)$ \\
\hline $20-24.99$ & $1.06(0.21)$ & $0.97(0.24)$ \\
\hline $25-29.99$ & $1.06(0.22)$ & $0.96(0.24)$ \\
\hline$\geqslant 30$ & $1.07(0.24)$ & $0.98(0.25)^{*}$ \\
\hline No hypertension & $1.06(0.21)$ & $0.98(0.24)$ \\
\hline Hypertension & $1.05(0.22)$ & $0.94(0.24)^{*}$ \\
\hline Low job control & $1.05(0.29)$ & $0.94(0.27)$ \\
\hline Medium job control & $1.07(0.20)$ & $1.00(0.20)$ \\
\hline High job control & $1.06(0.16)^{\text {** }}$ & $1.03(0.16)^{\text {** }}$ \\
\hline Low job demands & $0.88(0.18)$ & $0.81(0.19)$ \\
\hline Medium job demands & $1.06(0.16)$ & $1.03(0.18)$ \\
\hline High job demands & $1.21(0.19)^{* *}$ & $1.20(0.21)^{* *}$ \\
\hline Low support at work & $1.16(0.24)$ & $1.06(0.27)$ \\
\hline Medium support work & $1.05(0.18)$ & $0.97(0.20)$ \\
\hline High support at work & $0.97(0.16)^{* *}$ & $0.88(0.18)^{* *}$ \\
\hline Low intrinsic effort & $1.00(0.21)$ & $0.91(0.24)$ \\
\hline High intrinsic effort & $1.10(0.20)^{* *}$ & $1.04(0.22)^{* *}$ \\
\hline
\end{tabular}

from our baseline questionnaire that loaded onto factors similar to extrinsic effort and reward measured at phase 5. Numerous iterations led to factors that were tested against the Siegrist items at phase 5 (extrinsic effort and reward separately) using confirmatory factor analyses. We checked the internal consistency of both reward and extrinsic effort at each iterative stage in order to ensure unidimensionality of the constructs. Eventually, we identified five questions to measure extrinsic effort and 10 to measure rewards (these questions, together with their factor loading and Cronbach's alpha, are given in table 1). Given that the British Civil Service is essentially white collar, no questions on physical extrinsic effort were included in our extrinsic effort score. In both scales high scores denote high effort and high reward.

The methods of principal components analysis and confirmatory factor analysis were not successful in producing a closely related scale that measured intrinsic effort. For this reason we have used only the question "Has your work often stayed with you so that you were thinking about it after working hours?", as a measure of intrinsic effort. It seemed reasonable to use this single question, as psychometric analyses of the original scale measuring intrinsic effort (overcommitment) revealed that the items reflecting inability to withdraw from work obligations have the highest criterion validity. ${ }^{53}$ The question used to measure intrinsic effort was measured on a five point scale. This scale was dichotomised so that intrinsic effort was used as a binary variable in this study.

\section{Demographic and socioeconomic characteristics}

We obtained information on demographic characteristics from a self completed questionnaire at phase 1. Participants were asked to describe their civil service employment grade at the time of the baseline survey as a measure of SES, and they were then assigned to one of six grades based on salary scale. Grade 1 indicates participants in Unified Grades 1-6 (annual salary range at August 1992, £28 904-£87 620), grade 2 Unified 
Table 3 Cox proportional hazard derived hazard ratios of the association between phase 1 effort and reward at work and incident CHD during 11 years of follow up

\begin{tabular}{|c|c|c|c|c|c|c|}
\hline & \multicolumn{3}{|l|}{ All CHD } & \multicolumn{3}{|c|}{ Fatal CHD/non-fatal MI } \\
\hline & $\begin{array}{l}\text { Age and sex } \\
\text { adjusted }\end{array}$ & $\begin{array}{l}\text { Age, sex, and } \\
\text { grade adjusted }\end{array}$ & $\begin{array}{l}\text { Age, sex, grade, } \\
\text { and coronary risk } \\
\text { factor adjusted }\end{array}$ & $\begin{array}{l}\text { Age and sex } \\
\text { adjusted }\end{array}$ & $\begin{array}{l}\text { Age, sex, and } \\
\text { grade adjusted }\end{array}$ & $\begin{array}{l}\text { Age, sex, grade, } \\
\text { and coronary risk } \\
\text { factor adjusted }\end{array}$ \\
\hline \multicolumn{7}{|l|}{ Main model } \\
\hline Effort-reward ratio & 9870 (928) & 9870 (928) & $9004(843)$ & $10221(300)$ & $10221(300)$ & 9318 (272) \\
\hline Quartile 1 & Baseline & Baseline & Baseline & Baseline & Baseline & Baseline \\
\hline Quartile 2 & $0.96(0.80-1.16)$ & $1.05(0.86-1.27)$ & $1.01(0.82-1.24)$ & $1.23(0.87-1.73)$ & $1.42(1.01-2.02)$ & $1.44(1.00-2.08)$ \\
\hline Quartile 3 & $1.13(0.94-1.37)$ & $1.28(1.05-1.55)$ & $1.17(0.96-1.44)$ & $1.36(0.97-1.89)$ & $1.65(1.17-2.32)$ & $1.52(1.06-2.19)$ \\
\hline Quartile 4 & $1.22(1.01-1.46)$ & $1.36(1.12-1.65)$ & $1.26(1.03-1.55)$ & $1.06(0.74-1.51)$ & $1.28(0.89-1.84)$ & $1.21(0.82-1.78)$ \\
\hline \multirow[t]{2}{*}{ Trend } & $p=0.01$ & $p=0.0003$ & $p=0.008$ & $p=0.69$ & $p=0.17$ & $p=0.39$ \\
\hline & $9836(928)$ & $9836(928)$ & $8975(843)$ & $10185(300)$ & $10185(300)$ & 9287 (272) \\
\hline Low intrinsic effort & Baseline & Baseline & Baseline & Baseline & Baseline & Baseline \\
\hline High intrinsic effort & $1.18(1.03-1.34)$ & $1.29(1.13-1.48)$ & $1.26(1.09-1.46)$ & $1.22(0.96-1.54)$ & $1.41(1.11-1.81)$ & $1.24(0.96-1.60)$ \\
\hline \multicolumn{7}{|l|}{ Subsidiary models } \\
\hline & 9872 (928) & 9872 (928) & 9005 (843) & $10223(300)$ & $10223(300)$ & 9319 (272) \\
\hline Low effort & Baseline & Baseline & Baseline & Baseline & Baseline & Baseline \\
\hline Medium effort & $1.02(0.87-1.20)$ & $1.12(0.95-1.33)$ & $1.06(0.89-1.26)$ & $1.28(0.96-1.71)$ & $1.54(1.14-2.09)$ & $1.42(1.03-1.95)$ \\
\hline High effort & $1.03(0.88-1.20)$ & $1.22(1.02-1.45)$ & $1.07(0.89-1.28)$ & $1.08(0.82-1.44)$ & $1.45(1.06-1.98)$ & $1.28(0.92-1.78)$ \\
\hline \multirow[t]{2}{*}{ Trend } & $\mathrm{p}=0.75$ & $p=0.03$ & $p=0.46$ & $p=0.65$ & $p=0.03$ & $p=0.17$ \\
\hline & 9877 (931) & 9877 (931) & $9011(846)$ & $10228(300)$ & $10228(300)$ & $9325(272)$ \\
\hline Low rewards & $1.19(1.02-1.38)$ & $1.13(0.97-1.31)$ & $1.16(0.98-1.36)$ & $0.99(0.75-1.29)$ & $0.90(0.68-1.19)$ & $0.96(0.72-1.28)$ \\
\hline Medium rewards & $0.99(0.84-1.16)$ & $0.97(0.82-1.14)$ & $0.98(0.82-1.16)$ & $0.99(0.75-1.30)$ & $0.96(0.73-1.26)$ & $1.00(0.75-1.34)$ \\
\hline High rewards & Baseline & Baseline & Baseline & Baseline & Baseline & Baseline \\
\hline Trend & $p=0.03$ & $p=0.14$ & $p=0.09$ & $p=0.91$ & $p=0.45$ & $p=0.78$ \\
\hline
\end{tabular}

Grade 7 (£25 330-£36 019), grade 3 Senior Executive Officer (£18 082-£25 554), grade 4 Higher Executive Officer (£14 456-£20 850), grade 5 Executive Officer (£8517$£ 16668)$, and grade 6 Clerical and Office Support staff (£6483-£11 917). Other SES related factors were also recorded, including access to a car and home ownership.

\section{Traditional coronary risk factors}

We measured classical coronary risk factors in standard ways at the baseline screening. ${ }^{12}$ The following coronary risk factors were included: cigarette smoking ("never smokers", "exsmokers", and "current smokers: $\leqslant 10,11-20$, or $>20$ cigarettes/day"), serum cholesterol $(\mathrm{mmol} / \mathrm{l})$, hypertension (diastolic blood pressure $\geqslant 95 \mathrm{~mm} \mathrm{Hg}$, systolic blood pressure $\geqslant 160 \mathrm{~mm} \mathrm{Hg}$, or drug treatment for hypertension), exercise $(\geqslant 1.5$ or $<1.5$ hours of moderate or vigorous exercise per week), alcohol consumption (non-drinker, drinker at or below recommended limit set by the British government's Department of Health, drinker above the recommended limit) and body mass index (BMI) $\left(<20,20-24.9,25-29.9, \geqslant 30 \mathrm{~kg} / \mathrm{m}^{2}\right)$.

\section{Statistical analysis}

In order to assess the core theoretical notion of the ERI model, a ratio of the scales of extrinsic effort (numerator) and reward (denominator) was computed. Effort in the ERI model always refers to extrinsic effort, unless it is made explicit that intrinsic effort is the predictor variable. We calculated the mean and standard deviations of the self reported effort-reward ratio scores for each category of baseline variables, separately for men and women, using the statistical package SAS. Analysis of variance was used to test for significant differences in means between categories of baseline characteristics.

We constructed quartiles of the ratio to identify a high risk group in terms of the upper quartile, with the baseline (lowest) quartile indicating the most advantageous position of low efforts relative to rewards. We conducted survival analyses, using Cox proportional hazards models, to determine whether the ratio of efforts to rewards predicted incident non-fatal $\mathrm{MI} /$ fatal CHD or all CHD during follow up, excluding the par- ticipants with prevalent MI or all CHD at phase 1, respectively. We also used logistic regression analyses to assess the relation between baseline effort-reward ratio with, in turn, physical and mental functioning. The logistic regression models were restricted to participants who reported data on health functioning at phase 5 . These models were adjusted for age and stratified by gender, and were repeated using the single item measure of intrinsic effort as the predictor variable. The models were then successively adjusted for employment grade level, other SES indicators (home and car ownership), and traditional coronary risk factors (cigarette smoking, serum cholesterol, hypertension, exercise, alcohol consumption, and BMI, measured as indicated in the "traditional coronary risk factors" section). Tests for trends were performed, modelling the group scores of the psychosocial work variable $(1,2,3,4)$ as one variable.

To maintain consistency with analyses from other researchers we tested several combinations of effort and reward in the prediction of health outcomes, in addition to the core ratio measure, as subsidiary analyses. Effort and reward were used, separately and mutually adjusting, as predictors of CHD and health functioning. In addition, we calculated the four effortreward imbalance quadrants (high effort/low rewards, high effort/high rewards, low effort/low rewards, low effort/high rewards) by dichotomising effort and reward at the median and used these quadrants to predict events. We introduced an interaction term for effort and rewards into a regression model along with the main components (high efforts and low rewards) to test for a significant interaction between effort and rewards on the multiplicative scale in this model. We also successively adjusted these models for employment grade, other SES indicators, and traditional coronary risk factors. We stratified the age adjusted analyses by level of social support at work and intrinsic effort measured at baseline, in turn, to test for the potential buffering of the effect of adverse work characteristics by high social support at work or low intrinsic effort. We also assessed potential effect modification by grade (at three levels), age (four age groups), and father's social status (at four levels). 
Table 4 Logistic regression derived odds ratios of the association between phase 1 effort and reward at work and phase 5 health functioning

\begin{tabular}{|c|c|c|c|c|c|c|}
\hline & \multicolumn{3}{|c|}{ Poor physical functioning* } & \multicolumn{3}{|c|}{ Poor mental functioning* } \\
\hline & $\begin{array}{l}\text { Age and sex } \\
\text { adjusted }\end{array}$ & $\begin{array}{l}\text { Age, sex, and } \\
\text { grade adjusted }\end{array}$ & $\begin{array}{l}\text { Age, sex, and } \\
\text { coronary risk factor } \\
\text { adjusted }\end{array}$ & $\begin{array}{l}\text { Age and sex } \\
\text { adjusted }\end{array}$ & $\begin{array}{l}\text { Age, sex, and } \\
\text { grade adjusted }\end{array}$ & $\begin{array}{l}\text { Age, sex, and } \\
\text { coronary risk factor } \\
\text { adjusted }\end{array}$ \\
\hline \multicolumn{7}{|l|}{ Main model } \\
\hline Effort-reward ratio & 6918 (1728) & 6918 (1728) & 6399 (1592) & 6918 (1731) & 6918 (1731) & 6399 (1605) \\
\hline Quartile 1 & Baseline & Baseline & Baseline & Baseline & Baseline & Baseline \\
\hline Quartile 2 & $0.93(0.79-1.09)$ & $1.07(0.91-1.27)$ & $1.05(0.88-1.25)$ & $0.95(0.80-1.12)$ & $1.09(0.91-1.29)$ & $1.13(0.95-1.36)$ \\
\hline Quartile 3 & $1.04(0.89-1.22)$ & $1.25(1.06-1.48)$ & $1.20(1.01-1.43)$ & $1.24(1.05-1.46)$ & $1.47(1.24-1.75)$ & $1.46(1.22-1.75)$ \\
\hline Quartile 4 & $1.23(1.05-1.45)$ & $1.47(1.24-1.74)$ & $1.40(1.18-1.67)$ & $1.90(1.61-2.23)$ & $2.24(1.89-2.65)$ & $2.32(1.94-2.77)$ \\
\hline \multirow[t]{2}{*}{ Trend } & $p=0.003$ & $p=0.0001$ & $p=0.0001$ & $p=0.0001$ & $p=0.0001$ & $p=0.0001$ \\
\hline & 6905 (1727) & 6905 (1727) & $6386(1590)$ & 6905 (1727) & 6905 (1727) & 6386 (1601) \\
\hline Low intrinsic effort & Baseline & Baseline & Baseline & Baseline & Baseline & Baseline \\
\hline High intrinsic effort & $1.22(1.09-1.37)$ & $1.42(1.26-1.60)$ & $1.38(1.22-1.56)$ & $1.50(1.34-1.68)$ & $1.72(1.52-1.94)$ & $1.70(1.50-1.93)$ \\
\hline \multicolumn{7}{|l|}{ Subsidiary model } \\
\hline & 6919 (1729) & 6919 (1729) & 6399 (1592) & 6919 (1731) & 6919 (1731) & 6399 (1605) \\
\hline Low effort & Baseline & Baseline & Baseline & Baseline & Baseline & Baseline \\
\hline Medium effort & $0.91(0.79-1.05)$ & $1.06(0.92-1.23)$ & $1.04(0.89-1.21)$ & $0.88(0.76-1.01)$ & $0.98(0.85-1.14)$ & $0.96(0.83-1.12)$ \\
\hline High effort & $1.04(0.91-1.19)$ & $1.36(1.17-1.58)$ & $1.29(1.10-1.51)$ & $0.97(0.85-1.11)$ & $1.19(1.03-1.38)$ & $1.19(1.02-1.38)$ \\
\hline \multirow[t]{2}{*}{ Trend } & $p=0.53$ & $p=0.0001$ & $p=0.001$ & $p=0.69$ & $p=0.02$ & $p=0.03$ \\
\hline & $6923(1731)$ & $6923(1731)$ & 6399 (1592) & $6923(1731)$ & $6923(1731)$ & $6399(1605)$ \\
\hline Low rewards & $1.40(1.23-1.60)$ & $1.30(1.13-1.49)$ & $1.33(1.15-1.53)$ & $2.10(1.83-2.40)$ & $1.99(1.73-2.28)$ & $2.03(0.76-2.35)$ \\
\hline Medium rewards & $1.16(1.01-1.33)$ & $1.13(0.99-1.30)$ & $1.18(1.02-1.36)$ & $1.43(1.24-1.64)$ & $1.40(1.21-1.61)$ & $1.41(1.22-1.63)$ \\
\hline High rewards & Baseline & Baseline & Baseline & Baseline & Baseline & Baseline \\
\hline Trend & $p=0.0001$ & $p=0.0002$ & $p=0.0001$ & $p=0.0001$ & $p=0.0001$ & $p=0.0001$ \\
\hline
\end{tabular}

\section{RESULTS}

A high ratio of extrinsic effort to rewards was associated with high social class at phase 1 in both men and women, whether measured through employment grade or car and home ownership (table 2). In women, and to some extent in men, effort-reward ratio was higher in younger age groups. Although heavy drinkers reported a higher effort-reward ratio, there was no clear pattern with respect to cigarette smoking. People who exercised and those without hypertension reported a higher effort-reward ratio at work. High effort-reward ratio was also related to high job control, high job demands, and low social support at work. People with high intrinsic effort, measured by the single questionnaire item, were significantly more likely to report a high effort-reward ratio at work.

No difference was detected between men and women in the association between effort-reward ratio and health outcomes, and so joint analyses adjusted by sex are presented. Since high effort-reward ratio was associated with high employment grade, any analyses using effort-reward ratio as the predictor variable must be adjusted for employment grade to avoid the effects of negative confounding. After adjustment for employment grade, people who reported a high ratio of effort compared to rewards were at increased risk of both all CHD (hazard ratio $(\mathrm{HR})=1.36,95 \%$ CI 1.12 to 1.65 ) and, to some extent, fatal CHD/non-fatal MI (HR $=1.28,95 \%$ CI 0.89 to 1.84; table 3). The trend for risk of all CHD with increasing ratio of efforts to reward was highly statistically significant. This association persisted after additional adjustment for health behaviours ( $\mathrm{HR}=1.26,95 \%$ CI 1.03 to 1.55 ; and $\mathrm{HR}=1.21$, 95\% CI 0.82 to 1.78 for all CHD and fatal $\mathrm{CHD} /$ non-fatal MI, respectively). Furthermore, people with high perceived intrinsic effort, measured by one questionnaire item, were at increased risk of all CHD and of fatal CHD/nonfatal MI, which persisted after adjustment for employment grade and CHD risk factors.

In the grade adjusted subsidiary analyses, high effort was a significant predictor of all CHD ( $\mathrm{HR}=1.22,95 \% \mathrm{CI} 1.02$ to 1.45 ) and of fatal CHD/non-fatal MI (HR $=1.45,95 \%$ CI 1.06 to 1.98; table 3). Further adjustment for coronary risk factors somewhat diminished these associations. Low rewards were significantly related to the incidence of all CHD ( $\mathrm{HR}=1.19$, 95\% CI 1.02 to 1.38 ), but this association disappeared after adjustment for employment grade and traditional coronary risk factors, and there is no association with fatal CHD/nonfatal MI. Mutual adjustment for effort and rewards attenuated these associations little and people who were in the high effort and low reward quadrant were not at substantially increased risk of CHD (data not shown).

People with high efforts in relation to rewards at phase 1 were also at significantly increased risk of poor physical (odds ratio $(\mathrm{OR})=1.47,95 \% \mathrm{CI} 1.24$ to 1.74$)$ and mental functioning $(\mathrm{OR}=2.24,95 \%$ CI 1.89 to 2.65$)$ at phase 5, adjusting for employment grade (table 4). Adjustment for coronary risk factors had little effect (OR $=1.40,95 \%$ CI 1.18 to 1.67 for poor physical functioning, and OR $=2.32,95 \%$ CI 1.94 to 2.77 for poor mental functioning), and the trends were highly statistically significant. The single item measure of high intrinsic effort was also a significant predictor of both poor physical and mental health at phase 5 .

The grade adjusted subsidiary analyses show that high effort at phase 1 was a significant predictor of both poor physical functioning ( $\mathrm{OR}=1.36,95 \% \mathrm{CI} 1.17$ to 1.58$)$ and poor mental functioning ( $\mathrm{OR}=1.19,95 \% \mathrm{CI} 1.03$ to 1.38 ) at phase 5 , and additional adjustment for coronary risk factors had little effect. Furthermore, low rewards were strongly related to poor functioning, particularly with respect to poor mental functioning ( $\mathrm{OR}=1.99,95 \% \mathrm{CI} 1.73$ to 2.28 ), and this association persisted after adjustment for coronary risk factors. People with simultaneous high efforts and low rewards measured through the quadrant scale were at the highest risk of poor physical and mental functioning, but mutual adjustment for efforts and rewards had little effect (data not shown).

There was little evidence that a high ratio of effort to rewards was particularly deleterious among workers with high intrinsic effort measured by the single questionnaire item (table 5). In contrast, workers in the lower employment grades or with low social support suffered more from the 
Table 5 Effect modification of the association between the effort-reward ratio and health outcomes by intrinsic effort, employment grade, and social support at work

\begin{tabular}{|c|c|c|c|c|c|c|c|}
\hline & \multicolumn{2}{|l|}{ Intrinsic effort* } & \multicolumn{3}{|c|}{ Employment grade $†$} & \multicolumn{2}{|c|}{ Social support at work* } \\
\hline & $\begin{array}{l}\text { Think about } \\
\text { work after hours }\end{array}$ & $\begin{array}{l}\text { Do not think } \\
\text { about work after } \\
\text { hours }\end{array}$ & Administrative & Professional & Clerical & $\begin{array}{l}\text { Low social } \\
\text { support at work }\end{array}$ & $\begin{array}{l}\text { High social } \\
\text { support at work }\end{array}$ \\
\hline $\begin{array}{l}\text { All CHD } \\
\text { Effort-reward ratio }\end{array}$ & $5586(554)$ & 4244 (373) & $2929(242)$ & 4741 (441) & $2200(245)$ & 3395 (325) & 6401 (592) \\
\hline Quartile 1 & Baseline & Baseline & Baseline & Baseline & Baseline & Baseline & Baseline \\
\hline Quartile 2 & $\begin{array}{l}1.14 \\
(0.85-1.53)\end{array}$ & $\begin{array}{l}0.99 \\
(0.75-1.29)\end{array}$ & $\begin{array}{l}0.89 \\
(0.55-1.44)\end{array}$ & $\begin{array}{l}0.97 \\
(0.73-1.30)\end{array}$ & $\begin{array}{l}1.19 \\
(0.86-1.63)\end{array}$ & $\begin{array}{l}1.06 \\
(0.69-1.61)\end{array}$ & $\begin{array}{l}1.08 \\
(0.86-1.34)\end{array}$ \\
\hline Quartile 3 & $\begin{array}{l}1.51 \\
(1.14-2.00)\end{array}$ & $\begin{array}{l}0.92 \\
(0.68-1.25)\end{array}$ & $\begin{array}{l}1.15 \\
(0.73-1.80)\end{array}$ & $\begin{array}{l}1.31 \\
(1.00-1.73)\end{array}$ & $\begin{array}{l}1.00 \\
(0.68-1.48)\end{array}$ & $\begin{array}{l}1.46 \\
(1.00-2.15)\end{array}$ & $\begin{array}{l}1.27 \\
(1.01-1.60)\end{array}$ \\
\hline Quartile 4 & $\begin{array}{l}1.39 \\
(1.05-1.85)\end{array}$ & $\begin{array}{l}1.31 \\
(0.98-1.75)\end{array}$ & $\begin{array}{l}1.19 \\
(0.75-1.87)\end{array}$ & $\begin{array}{l}1.26 \\
(0.96-1.66)\end{array}$ & $\begin{array}{l}1.56 \\
(1.10-2.22)\end{array}$ & $\begin{array}{l}1.77 \\
(1.24-2.54)\end{array}$ & $\begin{array}{l}1.17 \\
(0.90-1.54)\end{array}$ \\
\hline $\begin{array}{l}\text { Fatal CHD/NF MI } \\
\text { Effort-reward ratio }\end{array}$ & 5801 (188) & 4378 (1 12) & 3007 (87) & 4908 (144) & $2306(69)$ & 3523 (95) & $6623(204)$ \\
\hline Quartile 1 & Baseline & Baseline & Baseline & Baseline & Baseline & Baseline & Baseline \\
\hline Quartile 2 & $\begin{array}{l}1.35 \\
(0.82-2.22)\end{array}$ & $\begin{array}{l}1.37 \\
(0.83-2.26)\end{array}$ & $\begin{array}{l}1.30 \\
(0.52-3.25)\end{array}$ & $\begin{array}{l}1.49 \\
(0.90-2.47)\end{array}$ & $\begin{array}{l}1.41 \\
(0.78-2.58)\end{array}$ & $\begin{array}{l}1.79 \\
(0.78-4.13)\end{array}$ & $\begin{array}{l}1.35 \\
(0.92-1.98)\end{array}$ \\
\hline Quartile 3 & $\begin{array}{l}1.59 \\
(0.98-2.56)\end{array}$ & $\begin{array}{l}1.33 \\
(0.77-2.30)\end{array}$ & $\begin{array}{l}1.99 \\
(0.84-4.71)\end{array}$ & $\begin{array}{l}1.62 \\
(0.98-2.69)\end{array}$ & $\begin{array}{l}1.03 \\
(0.49-2.19)\end{array}$ & $\begin{array}{l}2.26 \\
(1.03-4.94)\end{array}$ & $\begin{array}{l}1.56 \\
(1.05-2.31)\end{array}$ \\
\hline Quartile 4 & $\begin{array}{l}1.01 \\
(0.61-1.68)\end{array}$ & $\begin{array}{l}1.61 \\
(0.93-2.77)\end{array}$ & $\begin{array}{l}1.27 \\
(0.52-3.13)\end{array}$ & $\begin{array}{l}1.14 \\
(0.67-1.95)\end{array}$ & $\begin{array}{l}1.71 \\
(0.90-3.24)\end{array}$ & $\begin{array}{l}2.33 \\
(1.10-4.94)\end{array}$ & $\begin{array}{l}0.97 \\
(0.58-1.61)\end{array}$ \\
\hline $\begin{array}{l}\text { Poor physical } \\
\text { functioning } \\
\text { Effort-reward ratio }\end{array}$ & 4067 (1049) & $2833(675)$ & $2331(470)$ & $3473(820)$ & $1114(438)$ & $2302(653)$ & $4586(1066)$ \\
\hline Quartile 1 & Baseline & Baseline & Baseline & Baseline & Baseline & Baseline & Baseline \\
\hline Quartile 2 & $\begin{array}{l}1.10 \\
(0.86-1.42)\end{array}$ & $\begin{array}{l}1.03 \\
(0.82-1.31)\end{array}$ & $\begin{array}{l}1.11 \\
(0.75-1.64)\end{array}$ & $\begin{array}{l}0.95 \\
(0.75-1.21)\end{array}$ & $\begin{array}{l}1.23 \\
(0.90-1.68)\end{array}$ & $\begin{array}{l}0.80 \\
(0.57-1.13)\end{array}$ & $\begin{array}{l}1.17 \\
(0.96-1.42)\end{array}$ \\
\hline Quartile 3 & $\begin{array}{l}1.45 \\
(1.13-1.85)\end{array}$ & $\begin{array}{l}0.92 \\
(0.71-1.19)\end{array}$ & $\begin{array}{l}1.02 \\
(0.69-1.49)\end{array}$ & $\begin{array}{l}1.34 \\
(1.06-1.69)\end{array}$ & $\begin{array}{l}1.30 \\
(0.91-1.84)\end{array}$ & $\begin{array}{l}1.14 \\
(0.82-1.56)\end{array}$ & $\begin{array}{l}1.25 \\
(1.02-1.53)\end{array}$ \\
\hline Quartile 4 & $\begin{array}{l}1.61 \\
(1.26-2.04)\end{array}$ & $\begin{array}{l}1.10 \\
(0.84-1.44)\end{array}$ & $\begin{array}{l}1.38 \\
(0.94-2.02)\end{array}$ & $\begin{array}{l}1.60 \\
(1.27-2.02)\end{array}$ & $\begin{array}{l}0.86 \\
(0.58-1.26)\end{array}$ & $\begin{array}{l}1.30 \\
(0.96-1.75)\end{array}$ & $\begin{array}{l}1.39 \\
(1.11-1.75)\end{array}$ \\
\hline $\begin{array}{l}\text { Poor mental functioning } \\
\text { Effort-reward ratio }\end{array}$ & 4167 (1 127) & $2833(600)$ & $2331(462)$ & 3473 (910) & 1114 (359) & 2302 (682) & $4586(1036)$ \\
\hline Quartile 1 & Baseline & Baseline & Baseline & Baseline & Baseline & Baseline & Baseline \\
\hline Quartile 2 & $\begin{array}{l}0.90 \\
(0.70-1.16)\end{array}$ & $\begin{array}{l}1.20 \\
(0.94-1.54)\end{array}$ & $\begin{array}{l}1.01 \\
(0.65-1.56)\end{array}$ & $\begin{array}{l}0.96 \\
(0.75-1.22)\end{array}$ & $\begin{array}{l}1.30 \\
(0.94-1.81)\end{array}$ & $\begin{array}{l}1.07 \\
(0.75-1.53)\end{array}$ & $\begin{array}{l}1.08 \\
(0.88-1.33)\end{array}$ \\
\hline Quartile 3 & $\begin{array}{l}1.29 \\
(1.01-1.64)\end{array}$ & $\begin{array}{l}1.36 \\
(1.04-1.78)\end{array}$ & $\begin{array}{l}1.31 \\
(0.86-1.99)\end{array}$ & $\begin{array}{l}1.36 \\
(1.07-1.71)\end{array}$ & $\begin{array}{l}1.67 \\
(1.16-2.42)\end{array}$ & $\begin{array}{l}1.34 \\
(0.96-1.88)\end{array}$ & $\begin{array}{l}1.51 \\
(1.23-1.86)\end{array}$ \\
\hline Quartile 4 & $\begin{array}{l}1.95 \\
(1.54-2.46)\end{array}$ & $\begin{array}{l}1.85 \\
(1.40-2.45)\end{array}$ & $\begin{array}{l}2.10 \\
(1.40-3.17)\end{array}$ & $\begin{array}{l}2.08 \\
(1.66-2.60)\end{array}$ & $\begin{array}{l}2.20 \\
(1.51-3.20)\end{array}$ & $\begin{array}{l}2.19 \\
(1.60-3.00)\end{array}$ & $\begin{array}{l}2.05 \\
(1.64-2.57)\end{array}$ \\
\hline
\end{tabular}

adverse consequences of effort-reward imbalance with respect to CHD risk. There was no effect modification by father's social class or age (data not shown).

\section{DISCUSSION}

The effort-reward imbalance model is one of the two most influential models describing the association between stress in the work place and health outcomes. ${ }^{25}$ In this prospective study of civil servants based in London, we found an association between a high ratio of efforts to rewards and risk for CHD. We also found that high intrinsic effort (measured by a single questionnaire item), high efforts, and low rewards, respectively, predict the risk of CHD. These findings are confirmed for health functioning, whether using the physical or mental component of health functioning.

The results of our study confirm previous findings that ERI predicts the incidence of CHD. ${ }^{10}{ }^{1326}$ Moreover, ERI relates to risk of psychosomatic health complaints and physical health symptoms in both Western Europe ${ }^{27} 28$ and post-communist countries. ${ }^{29}$ The stronger effect of a ratio of effort to rewards, rather than the category of simultaneous high efforts and low rewards (that is, workers above the median for effort but below the median for rewards), in relation to health outcomes has been suggested previously, and may be the result of higher statistical power to observe an effect. ${ }^{29}$ The effect of effort-reward imbalance on CHD risk was slightly stronger among people with low social support at work or in lower employment grades, which is consistent with other studies. ${ }^{28} 30$

There is an inherent problem in studying the effect of psychosocial factors on health outcomes. Undeniably, poor psychosocial conditions are usually related to low SES, which, in turn, is independently related to health outcomes both through health behaviours as well as adverse childhood SES and, potentially, material deprivation. The question then remains, do psychosocial factors independently predict health outcomes, or is any association the effect of residual confounding by social class or health behaviours? The Whitehall II study provides an ideal setting in which to answer this question, since employment grade within the civil service provides an excellent measure of SES, as testified by its high correlation with income, assets, education, car and home ownership, and father's social class. This means that within Whitehall II adjustment for employment grade will be an adequate method of adjusting for the effect of SES. Furthermore, in this population, the adverse psychosocial characteristic of effort-reward imbalance, as well as high effort, is associated with higher, not lower, social class, yet both are significantly predictive of all CHD incidence and poor health functioning. This further weakens the argument that the association between psychosocial factors and health outcomes is merely the result of confounding by social class. What is more, the association between ERI and several of the 
health behaviours was not in the hypothesised direction, and an effect of ERI persisted after adjustment for traditional coronary risk factors.

There are two main hypothesised causal mechanisms for the association between ERI and health outcomes. The first mechanism is for a direct biological effect of ERI on the development of CHD. This proposed mechanism is supported by epidemiological evidence. In cross sectional studies ERI was associated with high blood pressure, ${ }^{31}{ }^{32}$ increased LDL cholesterol, ${ }^{31}$ increased fibrinogen, ${ }^{33}$ higher heart rate, and lower 24 hour vagal tone. ${ }^{34}$ Intrinsic effort alone also relates to an impaired fibrinolytic system, in terms of decreased tissue type plasminogen activator activity levels, and increased type 1 plasminogen activator inhibitor antigen concentrations. ${ }^{35}$ The second mechanism is for an effect of ERI on CHD risk through health behaviours, such as the uptake of smoking or failure to adhere to medical regimens. ${ }^{36-38}$ In the present study we found some weakening of the associations after adjustment for traditional coronary risk factors, supporting the argument that part of the association is through health behaviours. However, a substantial portion of the associations remained, indicating the possibility of a direct biological effect of ERI on health outcomes.

\section{Study strengths}

This study was large, included both men and women, and had a prospective design with extended follow-up. Furthermore, we included only cases of validated incident CHD among people who were disease free at baseline, minimising the potential for information bias. We evaluated psychosocial work characteristics on the basis of self report, rather than assigning scores by an external assessor; consequently scores accurately represented the individual's perceived work environment. To our knowledge, this is the first study to test prospectively the predictive power of the effort-reward imbalance model with regard to several health outcomes. Moreover, we analysed a theoretically grounded effect modification of intrinsic effort, age, social support at work, low employment grade, and father's social class.

\section{Study limitations}

Since the Whitehall II population is organisationally specific it could be argued that the results are not generalisable to other populations, partly as a result of different perception of job stressors in different organisations. ${ }^{39}$ However, earlier reports on the effects of psychosocial work characteristics on CHD incidence from Whitehall II have been in line with publications from other studies, ${ }^{1}$ and the study participants came from a range of social classes, diminishing the argument for lack of external validity. There was the potential for bias as a result of loss to follow up, particularly for the analyses using the SF-36 measures since they were conducted only on participants available at both phases 1 and 5. However, rates of loss to follow up were relatively low. Furthermore, since physical and mental functioning were not measured at phase l we could not adjust for these in the analyses and so there may be some confounding of the association between effortreward imbalance and health functioning at phase 5 by baseline health status.

The concept of effort-reward imbalance has been refined since the initial phase of the Whitehall II study. Therefore, the questions reflecting the most recent interpretation of this theory were not available at phase 1 and we used exploratory factor analysis to produce a satisfactory scale. The ERI scales constructed had high internal consistency, strengthening our confidence in this scale; however, should measurement error in ERI exist this is likely to be non-differential with respect to future health outcomes and therefore will bias the association between ERI and health outcomes towards the null. The ERI and the job demand control models may not be entirely

\section{Main messages}

- Subjects reporting high effort-reward imbalance were at an increased risk for coronary heart disease and poor health functioning during 11 years of follow up in a cohort of British Civil Servants.

- Subjects reporting high intrinsic effort, measured by a single questionnaire item, were also at increased risk of these health outcomes.

- Social support at work and high employment grade may buffer the adverse health effects of effort-reward imbalance.

- Although the effect of effort-reward imbalance on health is relatively small, it could be of considerable public health importance because of the high prevalence of effortreward imbalance.

\section{Policy implications}

- Organisations hoping for good mental and physical health of employees should aim to achieve a good balance between perceived effort expended by the employees and their reward structure. This could be achieved best by improving rewards rather than reducing efforts, for instance, by increasing praise received and encouraging individual development, as well as raising salaries.

- Improving social support at work could reduce the health risk associated with effort-reward imbalance at work.

- Intervention studies to evaluate the health effect of reducing effort-reward imbalance are timely and necessary.

distinct. However, intercorrelations of the scales of the two models are modest, with the exception of the scales "demand" and "effort", ${ }^{24}$ and several reports have documented an independent explanatory role for either model..$^{132284}$ In the current investigation a simultaneous analysis of the two models was not possible because of a substantial degree of overlap between the "demand" scale of the Karasek model and the "extrinsic effort" scale imputed from phase 1 items (Pearson's correlation $=0.84, \mathrm{p}<0.01)$. The correlations between decision latitude and extrinsic effort $(0.59, \mathrm{p}<0.01)$ and rewards $(0.50, \mathrm{p}<0.01)$ were also considerable, but the correlation between job demands and rewards was weaker $(0.10, p<0.01)$ There was also overlap in the questions used to measure "rewards" and "social support at work" which complicates interpretation of the effect modification of the ERI and health outcomes association by social support at work.

In conclusion, within the Whitehall II study, high efforts in relation to rewards predicted higher risk of coronary heart disease and poor physical and mental health functioning after 11 years of follow up. High efforts and low rewards also independently predicted poor health outcomes in the future. ERI was particularly deleterious with respect to CHD among people in low employment grades or who had low social support at work. Although the increased risk among those with ERI was small, the fact that these exposures are common means that they could be of considerable public health importance. Intervention studies to evaluate the health effects of reducing effort-reward imbalance are therefore timely and necessary. These interventions could act to increase rewards, rather than reduce efforts, perhaps through encouraging praise for good work, developing social supports at work, and ensuring that workers' skills are used in a variety of tasks. Should the interventions prove to be effective, policies focusing on redesigning jobs to reduce effort-reward imbalance or increase social support at work could be successful methods of workplace health promotion. 


\section{ACKNOWLEDGEMENTS}

The Whitehall II study has been supported by grants from the Medical Research Council; British Heart Foundation; Health and Safety Executive; Department of Health; National Heart Lung and Blood Institute (HL36310), US, NIH: National Institute on Aging (AG13196), US, NIH; Agency for Health Care Policy Research (HS06516); and the John D and Catherine T MacArthur Foundation Research Networks on Successful Midlife Development and Socioeconomic Status and Health. MM is supported by an MRC Research Professorship. We also thank all participating civil service departments and their welfare, personnel, and establishment officers; the Occupational Health and Safety Agency; the Council of Civil Service Unions; all participating civil servants in the Whitehall II study; and all members of the Whitehall II study team.

\section{Authors' affiliations}

H Kuper, A Singh-Manoux, M Marmot, International Centre for Health and Society, Department of Epidemiology and Public Health, University College London, 1-19 Torrington Place, London WC1E 6BT, UK J Siegrist, Department of Medical Sociology, Medical Faculty, Heinrich Heine Universität, Duesseldorf, PO 1010 07, Germany

\section{REFERENCES}

1 Kuper $\mathbf{H}$, Marmot $M$, Hemingway $H$. Emerging risk factors for coronary heart disease: updated systematic review of prospective cohort studies of psychosocial factors in the aetiology and prognosis of coronary heart disease. Semin Vasc Med. In press.

2 Minino AM, Smith BL. Deaths: preliminary data for 2000. Natl Vital Stat Rep 2001;49: 1-40

3 Karasek RA. Job demands, job decision latitude, and mental strain implications for job redesign. Adm Sci Q 1979;24:285-308.

4 Karasek RA, Theorell T. Healthy work: stress, productivity, and the reconstruction of working life. New York: Basic Books, 1990.

5 Siegrist J. Adverse health effects of high effort-low reward conditions at work. J Occup Health Psychol 1996;1:27-43.

6 Kaplan JR, Manuck SB, Shively CA, et al. Psychosocial factors, sex differences, and atherosclerosis: lessons from animal models. Psychosom Med 1996;58:598-611.

7 Siegrist J. A theory of occupational stress. In: Dunham J, ed. Stress in the workplace. Past, present and future. London: Whurr Publishers, 2000:63-6.

8 Johnson JV, Hall EM. Job strain, work place, social support and cardiovascular disease. Am J Public Health 1988;78:1336.

9 Johnson JV, Hall EM, Theorell T. Combined effects of job strain and social isolation on cardiovascular morbidity and mortality in a random sample of the Swedish male working population. Scand J Environ Health 1989:15:271-9.

10 Lynch J, Krause N, Kaplan GA, et al. Workplace conditions, socioeconomic status, and the risk of mortality and acute myocardial infarction: the Kuopio Ischemic Heart Disease Risk Factor Study. Am J Public Health 1997:87:617-22.

11 Macleod J, Smith GD, Heslop P, et al. Are the effects of psychosocial exposures attributable to confounding? Evidence from a prospective observational study on psychological stress and mortality. J Epidemiol Community Health 2001;55:878-84

12 Marmot MG, Smith GD, Stansfeld S, et al. Health inequalities among British civil servants: the Whitehall II study. Lancet 1991;337:1387-93.

13 Bosma H, Peter R, Siegrist J, et al. Two alternative job stress models and the risk of coronary heart disease. Am J Public Health 1998;88:68-74.

14 Stansfeld SA, Fuhrer R, Shipley M, et al. Work characteristics predict psychiatric disorder: prospective results from the Whitehall II Study. Occup Environ Med 1999:56:302-7.

15 Stansfeld SA, Bosma H, Hemingway $\mathrm{H}$, et al. Psychosocial work characteristics and social support as predictors of SF-36 health functioning: the Whitehall II study. Psychosom Med 1998;60:247-55

16 World Health Organization. International Classification of Diseases-9th revision. Geneva: World Health Organization, 1977.
17 Rose GA, Blackburn H, Gillum RF, et al. Cardiovascular survey methods, 2nd edn. Geneva: WHO, 1982

18 Macfarlane P. Methodology of ECG interpretation in the Glasgow program. Meth Inform Med 1990;29:354-61

19 Ware JE, Donald Shebourne C. The MOS 36-item short-form health survey (SF-36). I. Conceptual framework and item selection. Med Care 1992;30:473-83.

20 Hemingway $\mathbf{H}$, Nicholson A, Stafford $M$, et al. The impact of socioceonomic status on health functioning as assessed by the SF-36 questionnaire: the Whitehall II study. Am J Public Health 1997:87:1484-90.

21 Ware JE, Kosinski M, Keller SD. SF-36 Physical and Mental Health Summary Scales: a user's manual. Boston, MA: The Health Institute, 1994.

22 Niedhammer I, Siegrist J, Landre $M$, et al. Etude des qualities psychometriques de la version francaise du modele du d'sequilibre efforts/recompenses. Rev Epidemiol Sante Publique 1998;48:419-37.

23 Hanson EKS, Schaufeli W, Vrijkotte T, et al. The validity and reliability of the Dutch effort-reward imbalance questionnaire. J Occup Health Psychol 2000:5: 142-55

24 Tsutsumi A, Ishitake T, Peter R, et al. The Japanese version of the Effort-Reward-Imbalance Questionnaire: a study in dental technicians. Work \& Stress 2001;15:86-96.

25 Schnall PL, Belkic K, Landsbergis $\mathrm{P}$, et al. The workplace and cardiovascular disease. Occupational Medicine State of the Art Reviews 2000;15: 1-374.

26 Siegrist J, Peter R, Junge A, et al. Low status control, high effort at work and ischemic heart disease: prospective evidence from blue-collar men. Soc Sci Med 1990;31:1 129-36.

27 van Vegchel $\mathbf{N}$, de Jonge J, Meijer T, et al. Different effort constructs and effort-reward imbalance: effects on employee well-being in ancillary health care workers. J Adv Nurs 2001;34:128-36.

28 Jonge J de, Bosma $\mathrm{H}$, Siegrist J. Job strain, effort-reward imbalance and employee well-being: a large scale cross-sectional study. Soc Sci Med 2000:50:1317-27.

29 Pikhart H, Bobak M, Siegrist J, et al. Psychosocial work characteristics and self-rated health in four post-communist countries. J Epidemiol Community Health 2001;55:624-30.

30 Bakker $\mathbf{A B}$, Kilmer $\mathrm{CH}$, Siegrist J, et al. Effort-reward imbalance and burnout among nurses. J Adv Nurs 2000;31:884-91

31 Siegrist J, Peter R, Georg W, et al. Psychosocial and biobehavioral characteristics of hypertensive men with elevated atherogenic lipids. Atheroclerosis 1991:86:211-18.

32 Peter R, Alfredson L, Hammar N, et al. High effort, low reward, and cardiovascular risk factors in employed Swedish men and women: baseline results from the WOLF Study. J Epidemiol Community Health 1998;52:540-7.

33 Siegrist J, Peter R, Cremer $\mathrm{P}$, et al. Chronic work stress is associated with atherogenic lipids and elevated fibrinogen in middle-aged men. J Intern Med 1997;242:149-56

34 Vrijkotte TGM, van Doornen LJP, de Geus EJC. Effects of work stress on ambulatory blood pressure, heart rate, and heart rate variability. Hypertension 2000;35:880-6

35 Vrijkotte TGM, van Doornen LJP, de Geus EJC. Work stress and metabolic and hemostatic risk factors. Psychosom Med 1999;61:796-805.

36 Pieper C, LaCroix AZ, Karasek RA. The relation of psychosocial dimensions of work with coronary heart disease risk factors: a meta-analysis of five United States data bases. Am J Epidemio 1989; 129:483-94.

37 Green KL, Johnson JV. The effects of psychosocial work organization on patterns of cigarette smoking among male chemical plant employees. Am J Public Health 1990:80:1368-71.

38 Landsbergis PA, Schnall PL, Deitz DK, et al. Job strain and health behaviors: results of a prospective study. Am J Health Promot 1998; 12:237-45.

39 Kittel F, Kornitzer M, Dramaik M. Coronary heart disease and job stress in two cohorts of bank clerks. Psychother Psychosom 1980;34:110-23.

40 Peter R, Siegrist J, Hallqvist J, et al. Psychosocial work environment and myocardial infarction: improving risk estimation by combining two complimentary job stress models in the SHEEP Study. J Epidemiol Community Health 2002;56:294-300. 